\title{
(2) OPEN ACCESS \\ Inadequate completion of advance care directives by individuals with dementia: national audit of health and aged care facilities
}

\author{
Jamie Bryant (D) , 1,2,3 Marcus Sellars (D) , 4,5 Craig Sinclair, 6,7,8 \\ Karen Detering, ${ }^{4,9}$ Kimberly Buck, ${ }^{4}$ Amy Waller, ${ }^{1,2,3}$ Ben White (D) ,5 \\ Linda Nolte ${ }^{4}$
}

For numbered affiliations see end of article.

\section{Correspondence to} Dr Jamie Bryant, School of Medicine and Public Health, Health Behaviour Research Collaborative, The University of Newcastle, Callaghan, NSW 2308, Australia;

jamie.bryant@newcastle.edu.au

Received 1 November 2020 Revised 6 December 2020 Accepted 9 December 2020

\section{Check for updates}

(c) Author(s) (or their employer(s)) 2021. Re-use permitted under CC BY-NC. No commercial re-use. See rights and permissions. Published by BMJ.

\begin{tabular}{|l|}
\hline To cite: Bryant J, Sellars M, \\
Sinclair C, et al. BMJ \\
Supportive \& Palliative \\
Care Epub ahead of \\
print: [please include Day \\
Month Year]. doi:10.1136/ \\
bmjspcare-2020-002767
\end{tabular}

\section{ABSTRACT}

Objectives (i) Describe the prevalence and type of advance care directives (ACDs) and other advance care planning (ACP) documentation completed by persons with dementia, healthcare providers and others on behalf of a person with dementia; (ii) identify the personal and ACP programme characteristics associated with having ACP documentation in the health record; (iii) identify the personal and ACP programme characteristics associated with having a selfcompleted ACD.

Methods A multicentre audit was undertaken in Australian hospitals, general practices and residential aged care facilities. Auditors extracted demographic and ACP data from the records of eligible patients. ACP programme characteristics were provided by a site representative. Logistic and multinomial regression were used respectively to examine the factors associated with completion of any ACP documentation, and self-completion of an ACD by persons with dementia.

Results A total of 1388 people with dementia (33.2\%) from 96 sites were included. Overall, $60.8 \%(n=844)$ had ACP documentation; $31.6 \%$ $(\mathrm{n}=438)$ had a self-completed ACD and $29.3 \%$ $(\mathrm{n}=406)$ had an ACP document completed by a health professional or someone else on their behalf. Older participants were more likely to have ACP documented. Multivariate analyses indicated the odds of having self-completed ACP documents, compared with no advance care plan or ACP completed by someone else, were significantly influenced by age, country of birth, setting and whether the site had ACP training, policies or guidelines.

Discussion While $60 \%$ of people with dementia had some form of ACP documentation, only half of the cases in which ACP was documented included an ACD completed by the person themselves.

\section{INTRODUCTION}

Dementia is a neurodegenerative condition characterised by the progressive deterioration of memory, thinking, behaviour and the ability to perform activities of daily living. ${ }^{1}$ One-third of older people will die from dementia, with residential aged care facilities (RACFs) the most common site of death. ${ }^{2}$ There is increasing evidence that people with dementia face significant challenges in accessing appropriate end of life care. For people with dementia, the last year of life is often characterised by pain, agitation, pressure ulcers and pneumonia; limited access to palliative care services; and receipt of potentially futile treatments. $^{2-5}$ As dementia progresses, a person's capacity to independently make and communicate decisions deteriorates, and decisions will then often require the involvement family members or carers, ${ }^{2}$ who may be uncertain about the preferences of their loved one. ${ }^{6}$ Improving the quality of end-of-life care provided to people with dementia is a recognised priority worldwide. $^{78}$

Advance care planning (ACP) is a process whereby an individual considers and discusses their values and preferences about future healthcare, in case they later experience periodic, temporary or permanent loss of capacity. ${ }^{9}$ ACP is widely recognised as a key mechanism for improving the quality of care delivered to people with dementia. ${ }^{10-12}$ ACP has been associated with significant reductions in rates of hospitalisation and increased use of hospice services among those with dementia, ${ }^{13}$ as well as reduced stress, anxiety, and depression in surviving relatives in general medical settings. ${ }^{14}$ In 
Australia, ACP discussions may lead to the completion of an advance care directive (ACD), a written document recognised by common law or legislation. ${ }^{15}$ ACDs enable a person to give instructions about their preferences regarding future care and/or appoint a substitute decision maker (SDM) to make decisions on their behalf when they are unable to do so themselves. In addition to ACDs completed by the person, in some situations ACP documents may be completed on the person's behalf due to a temporary or ongoing loss of decision-making capacity. This may be by a member of the person's family or a healthcare professional involved in the person's care-such ACP documents are not considered legally binding, but can be helpful in guiding clinicians when making treatment decisions. ${ }^{16}$

Given the unpredictable trajectory of dementia and cognitive decline, it is important that people with dementia are engaged in ACP as early as possible to ensure they can be meaningfully involved in decision making. However, it is estimated that less than $40 \%$ of people with dementia undertake ACP internationally. ${ }^{61718}$ Factors contributing to the low uptake of ACP among people with dementia remain unclear. Different factors are associated with completion of ACDs regarding preferences for future care or nomination of SDMs, suggesting there may be differences in the types of people that complete different types of ACDs and their motivations for doing so. ${ }^{19}$ In studies of people with cognitive impairments, rates of engagement in ACP are higher among those with milder cognitive impairment, ${ }^{20}$ higher levels of education ${ }^{20}$ and those diagnosed at a younger age. ${ }^{17}$ These findings suggest that encouraging ACP during the early stages of dementia may enable participation prior to significant declines in cognitive function. However, qualitative studies have shown that responses to a dementia diagnosis differ, with some preferring to maintain a focus on the present and avoid thinking about the future. ${ }^{21} 22$

A number of healthcare professional and health service factors have also been shown to influence ACP uptake. ${ }^{19}$ Healthcare professionals may be reluctant to initiate ACP discussions with a person with dementia due to concerns about the person's decision-making capacity, especially if they feel under-prepared or under-trained to have these complex discussions. ${ }^{23-25}$ Even those who accept responsibility for initiating ACP discussions may be uncertain about when to initiate them, or lack time or resources to do so. ${ }^{23-25}$ Health service, organisation and system-wide factors, such as complexity and variation in legislation across jurisdictions, also influence ACP uptake. State-specific statutory legislation supporting ACDs result in different procedural requirements, with some states relying on non-statutory ACDs under common law precedent. This can create uncertainty and confusion about the requirements of ACP, its legal force, and the role of appointed SDMs. ${ }^{23}$ Dedicated organisational policies and procedures regarding ACP documentation, and systematic processes to ensure documented plans can be retrieved, have been shown to support implementation of ACP. ${ }^{23}$

Given these unique complexities associated with ACP in dementia care, it is important to understand participation in the ACP process by people with dementia, their family members or SDMs, and health professionals involved in their care. Greater understanding of participation of persons with dementia in ACP, and the personal and ACP programme characteristics associated with ACD completion, can help identify those most at risk of not being involved in ACP decisions.

Therefore, the aims of this study were to:

1. Describe the prevalence and type of ACDs and ACP documentation completed by (i) persons with dementia, (ii) healthcare providers and (iii) family, carers or someone else on behalf of a person with dementia.

2. Identify the personal and ACP programme characteristics associated with people with dementia having any ACP documentation identified in their health record.

3. Identify the personal and ACP programme characteristics associated with people with dementia having a selfcompleted ACD.

\section{METHODS}

\section{Design}

As part of an Australia-wide study to describe the prevalence of ACD and ACP documentation across health and aged care settings, ${ }^{26-28}$ a prospective multicentre audit was undertaken. This paper reports a secondary analysis of data presenting the findings of individuals with a diagnosis of dementia.

\section{Setting}

Hospitals, general practices (GPs) and RACFs located in all eight Australian states and territories.

\section{Site recruitment, eligibility and data collection}

An expression of interest (EOI) process was used to identify interested eligible sites for participation. Information about the study was distributed through peak organisation newsletters, websites and social media; via email and letter to primary health networks; at conferences; and via advertisement in academic journals and key stakeholder groups. Information included a description of the study, what would be required of participating sites, and the application process. Registered GPs, hospitals and RACFs were eligible to apply if they had access to a minimum of 30 health records likely to meet inclusion criteria, and resources to support implementation of the protocol. All sites that applied met eligibility criteria and were invited to participate. A proactive recruitment strategy (cold calling) was undertaken across all three sectors to ensure representativeness across jurisdictions and settings in the final sample. The EOI application form captured ACP programme data for each site, with the applicant 
for each participating site asked to self-report: whether the site had an ACP programme (eg, ACP offered as part of routine practice, eg, during a routine health assessment); whether ACP training is offered to staff; whether the site had any ACP policy or guidelines; and whether the site had any staff specifically funded to support ACP activities (eg, facilitate ACP conversations; assist with completion of documents).

\section{Participant eligibility}

Individuals were eligible for inclusion in the record audit if they were aged 65 years or older. Participants in hospital and RACF settings were required to be admitted for at least 48 hours prior to the conduct of the audit. Participants recruited from GPs were those attending on the study day.

\section{Participant selection}

In RACFs and hospitals, a deidentified sample of patients/clients matching the inclusion criteria was drawn from the electronic patient information management system on the day the audit was conducted. An online research randomisation tool was then used to randomise records as either included or not included in the audit. Data extraction was then undertaken for the agreed number of records. In GP, files of eligible individuals consecutively visiting the practice on the day(s) of the audit were identified and included. The number of records audited per participating site was between 30 and 50 .

\section{Participant data collection}

Data were collected over a 4-month period between October 2018 and January 2019. As only deidentified data were collected, a waiver for the requirement of individual patient consent was obtained. Audits were principally conducted by an employee from each participating site who was trained by a member of the research team. For sites that did not have staff to undertake audits, a trained independent auditor (who was not part of the research team) undertook data collection. Auditors examined each selected paper and/or electronic health record at each facility for a maximum of $15 \mathrm{~min}$. This timeframe was chosen because in order to be useful in practice, documentation needs to be quickly and easily accessible. Demographic and clinical information was recorded using an electronic form.

\section{Measures}

The following information was recorded for each participant.

\section{Demographic characteristics}

Age, gender, postcode, country of birth, current relationship status and English speaking.

\section{Clinical information}

Auditors recorded whether each person had any of the following medical conditions (current or active): cancer; dementia; heart conditions; respiratory conditions; chronic kidney conditions; endocrine, nutritional and metabolic disorders; gastrointestinal conditions; neurological conditions; urinary or reproductive conditions; mental health conditions. Auditors also recorded whether each person had been receiving palliative care (yes/no/unknown); and the person's Eastern Cooperative Oncology Group (ECOG) performance status as noted in the medical records (grade $0-4$ or 'not available'). ${ }^{29}$ If ECOG status was not available (the majority of records), the auditor provided an estimate of the person's likely functional status following review of their health record as a whole using six defined categories: no disability (fully active, able to carry out all daily living activities); some disability (restricted in physically strenuous activity, but ambulatory and able to carry out work of a light or sedentary nature, eg, light housework, office work); moderate disability (ambulatory and capable of all selfcare but unable to carry out any work activities); severe disability (capable of only limited self-care; confined to bed or chair more than $50 \%$ of waking hours); very severe disability (completely disabled; unable to carry out any self-care; totally confined to bed or chair). If they were unable to estimate likely degree of disability, they selected 'insufficient information available'.

\section{Presence of ACDs}

A self-completed ACD was defined as 'a type of written structured advance care plan recognised by common law or specific legislation that is completed and signed by a competent adult'. Auditors were trained to identify ACDs recognised by state-based legislation (statutory ACDs) and/or formal documents recognised under common law (non-statutory ACDs). ${ }^{28}$ The type of ACD located (statutory/non-statutory) and whether it recorded preferences for care or appointed an SDM was recorded. The type of ACD identified and who completed the document was also recorded.

ACP documentation completed by health professionals, or someone else on behalf of the person

Auditors identified ACP documentation completed by a health professional ('an advance care plan completed by a staff member for the person') or someone else ('an advance care plan completed on behalf of the person, eg, by an SDM').

\section{Statistical analysis}

Analyses were conducted using SPSS V.26. Descriptive statistics were used to present demographic characteristics for the sample and sites. Auditor-assessed functional status, or ECOG status for those with this recorded, were combined to represent estimated functional status. ${ }^{28}{ }^{30}$ For site-level variables, unsure 
and no responses were combined for the purpose of regression analysis. States were recoded into those states with legislation for documentation of ACD preferences (Victoria, Queensland, South Australia, Northern Territory, Australian Capital Territory and Western Australia and those where ACD preferences are recognised by common law (New South Wales and Tasmania). Those who selected 'other' for gender were excluded from the model due to the low count. Logistic regression was used to assess the relation of person and site level variables with any ACP document completion. Multivariable multinomial mixed effects logistic regression was used to assess the relation of person and site level variables with the ACP document completion outcome. Three groups composed the outcome: 'ACD completed by self', 'ACP document completed by other' and 'no ACD or advance care plan'. Those who had self-completed ACD as well as ACP document completed by other were classified as having selfcompleted ACD. A random intercept with independent covariance structure was used to account for clustering of observations by site. For each independent variable crude effects were assessed. Linearity of the log odds of the outcome was assessed for age using the BoxTidwell test. A full model was constructed with all the independent variables including person-level variables and site-level variables to derive adjusted effects. A pseudo intraclass correlation (ICC) is reported for each model to describe the relative variance explained by individual-level and site-level variables.

\section{RESULTS}

A total of 100 sites participated in the study. Of 4187 records audited, 1388 people (33.2\%) from 96 sites (13 GPs, 25 hospitals and 58 RACFs) had dementia and were included in the analysis. Participant characteristics are provided in table 1. Site characteristics are provided in table 2 . The majority of participants were residing in RACF settings (88.9\%), multimorbid $(84.5 \%)$, with severe or very severe disability (74.2\%).

\section{Prevalence and type of ACP documentation}

Prevalence of ACP documentation by type and setting are presented in table 3. Overall, 31.6\% $(n=438)$ of participants had a self-completed ACD, 29.3\% $(n=406)$ had an ACP document either completed by a health professional or someone else on their behalf only, and $39.2 \%(n=544)$ had no ACD or ACP documentation. Of those with self-completed ACD, the largest proportion had a statutory ACD appointing an SDM (17.3\%).

\section{Factors associated with ACP completion}

Results of the logistic regression examining associations with any ACP document completion are provided in table 4 . The site effect was estimated as 1.313 (pseudo ICC $=0.285$ ). In the adjusted model, 153 participants were excluded due to missing data; a sensitivity

\begin{tabular}{|c|c|c|c|}
\hline & Mean & SD & \\
\hline \multirow[t]{2}{*}{ Age } & 85.3 & 7.4 & \\
\hline & & $\mathrm{N}$ & $\%$ \\
\hline \multirow[t]{3}{*}{ Gender } & Male & 465 & 33.5 \\
\hline & Female & 919 & 66.2 \\
\hline & Other & 4 & 0.3 \\
\hline \multirow[t]{3}{*}{ Setting } & GP & 20 & 1.4 \\
\hline & Hospital & 134 & 9.7 \\
\hline & RACF & 1234 & 88.9 \\
\hline \multirow[t]{8}{*}{ State } & New South Wales & 515 & 37.1 \\
\hline & Victoria & 328 & 23.6 \\
\hline & Queensland & 276 & 19.9 \\
\hline & South Australia & 182 & 13.1 \\
\hline & Australian Capital Territory & 39 & 2.8 \\
\hline & Western Australia & 30 & 2.2 \\
\hline & Northern Territory & 16 & 1.2 \\
\hline & Tasmania & 2 & 0.1 \\
\hline \multirow{5}{*}{$\begin{array}{l}\text { Relationship } \\
\text { status }\end{array}$} & Married/living with partner & 289 & 28.0 \\
\hline & Divorced/separated & 127 & 9.1 \\
\hline & Widowed & 674 & 48.6 \\
\hline & Single & 110 & 7.9 \\
\hline & Unknown & 88 & 6.3 \\
\hline \multirow[t]{3}{*}{ Language } & English speaking & 1222 & 88.0 \\
\hline & Non-English speaking & 142 & 10.2 \\
\hline & Unknown & 24 & 1.7 \\
\hline \multirow[t]{3}{*}{ Country of birth } & Australia & 883 & 63.6 \\
\hline & Other & 465 & 33.5 \\
\hline & Not available & 40 & 2.9 \\
\hline \multirow[t]{3}{*}{ Morbidity } & Unimorbid & 62 & 4.5 \\
\hline & Comorbid & 153 & 11.0 \\
\hline & Multimorbid & 1173 & 84.5 \\
\hline \multirow{2}{*}{$\begin{array}{l}\text { Receiving } \\
\text { palliative care }\end{array}$} & Yes & 127 & 9.1 \\
\hline & No & 1237 & 89.1 \\
\hline \multirow{6}{*}{$\begin{array}{l}\text { Estimated } \\
\text { functional status }\end{array}$} & No disability & 5 & 0.4 \\
\hline & Some disability & 52 & 3.7 \\
\hline & Moderate disability & 279 & 20.1 \\
\hline & Severe disability & 664 & 47.8 \\
\hline & Very severe disability & 367 & 26.4 \\
\hline & Not available & 21 & 1.5 \\
\hline \multirow{10}{*}{$\begin{array}{l}\text { Medical } \\
\text { condition(s) } \\
\text { in addition to } \\
\text { dementia* }\end{array}$} & Cancer (malignant) & 165 & 11.9 \\
\hline & Heart condition & 758 & 54.6 \\
\hline & Respiratory condition & 264 & 19.0 \\
\hline & Chronic kidney condition & 131 & 9.4 \\
\hline & Endocrine/metabolic/nutritional & 425 & 30.6 \\
\hline & Gastrointestinal condition & 359 & 25.9 \\
\hline & Neurological condition & 309 & 22.3 \\
\hline & Urinary or reproductive condition & 428 & 30.8 \\
\hline & Mental health condition & 614 & 44.2 \\
\hline & Musculoskeletal/connective tissue & 848 & 61.1 \\
\hline
\end{tabular}

*Participant may have more than one (other) medical condition. GP, general practice; RACF, residential aged care facility.

analysis was performed where the missing values were included as separate levels of the variables in order to enable these participants to be included. The estimated 


\begin{tabular}{|c|c|c|c|}
\hline & & $\mathrm{N}$ & $\%$ \\
\hline \multirow[t]{3}{*}{ ACP programme } & Yes & 78 & 81.3 \\
\hline & No & 16 & 16.7 \\
\hline & Unsure & 2 & 2.1 \\
\hline \multirow{3}{*}{$\mathrm{ACP}$ training for staff } & Yes & 67 & 69.8 \\
\hline & No & 19 & 19.8 \\
\hline & Unsure & 10 & 10.4 \\
\hline \multirow[t]{3}{*}{ ACP policy or guideline } & Yes & 60 & 62.5 \\
\hline & No & 30 & 31.3 \\
\hline & Unsure & 6 & 6.3 \\
\hline \multirow[t]{2}{*}{ Staff funded to implement ACP } & Yes & 18 & 18.8 \\
\hline & No & 78 & 81.3 \\
\hline
\end{tabular}

ORs were highly consistent between both models, with the effect of 'any funded ACP support' reaching statistical significance with the additional participants included ( $p=0.037$; results not shown in table 4$)$. In the adjusted model, older participants were more likely to have ACP documented $(\mathrm{OR}=1.03, \mathrm{p}=0.009)$. Participants born in a country other than Australia $(\mathrm{OR}=0.68, \mathrm{p}=0.019)$ and those who did not reside in an RACF $(\mathrm{OR}=0.15, \mathrm{p}<0.001)$ were less likely to have ACP documented.

Results of the multinomial regression examining associations between self-completed ACDs, those who only had ACP documentation completed by someone else, and those with no ACD or advance care plan, are provided in table 5. The estimate of site variance component for two comparisons were 1.136 and 1.375 (pseudo ICC $=0.257$ and 0.295 ). In the adjusted model, 153 participants were excluded due to missing data. A sensitivity analysis was performed where the missing values were included as separate levels of the variables in order to enable these participants to be included. The estimated ORs were highly consistent between both models.

Age, country of birth, setting, whether the site had ACP training, and whether the site had an ACP policy or guidelines were all significantly associated with having a self-completed ACD. Older participants had greater odds of having a self-completed ACD $(\mathrm{OR}=0.97)$, relative to those with no ACP documentation, than those who were 1 year younger. Those with a self-completed ACD had greater odds of being born in Australia $(\mathrm{OR}=1.59)$, sampled from an RACF $(\mathrm{OR}=3.17)$ and sampled from a site that reported having an ACP policy or guideline $(\mathrm{OR}=1.39)$, relative to those with no advance care plan or ACD. However, those with a self-completed ACD had lower odds of being from a site with ACP training $(\mathrm{OR}=0.37)$ relative to those with no advance care plan or ACD. Relative to participants that had ACP completed by someone else on their behalf, participants with a self-completed ACD had greater odds of being born in Australia ( $\mathrm{OR}=1.15)$, and sampled from a site that reported having an ACP policy or guideline $(\mathrm{OR}=3.05)$. However, those with a self-completed ACD had lower odds of being sampled from an RACF setting $(\mathrm{OR}=0.20)$, and sampled from a site with ACP training $(\mathrm{OR}=0.09)$, relative to those that had ACP completed by someone else on their behalf.

\section{DISCUSSION}

This study is the first to provide data about the prevalence and type of ACP documentation in the health records of persons with dementia across health and aged care settings in Australia.

This multicentre audit found that while $60 \%$ of those with dementia had some form of ACP documentation in their health record, only half of those had an ACD completed by the person themselves. This rate is somewhat higher than that reported in previous community-based cohort studies, ${ }^{17}$ and may reflect the high proportion of participants with multimorbidity in RACF settings, suggesting that participants overall had reached a more advanced stage of dementia. The rates observed here are comparable to those reported in a retrospective (postdeath) survey of family members of people who died with a diagnosis of dementia. ${ }^{31}$

Table 3 Presence and type of ACP documentation completed by persons with dementia, or someone on behalf of the person with dementia, in each heath and aged care setting and overall $(n=1388)$

\begin{tabular}{|c|c|c|c|c|}
\hline Presence of ACP documentation & $\begin{array}{l}\text { GP } \\
\text { N (\%) }\end{array}$ & $\begin{array}{l}\text { Hospital } \\
\text { N (\%) }\end{array}$ & $\begin{array}{l}\text { RACF } \\
\text { N (\%) }\end{array}$ & $\begin{array}{l}\text { Overall } \\
\mathrm{N}(\%)\end{array}$ \\
\hline No ACD or advance care plan & $14(70)$ & $105(78.4)$ & $425(34.4)$ & $544(39.2)$ \\
\hline Self-completed ACD* & $5(25.0)$ & $21(15.7)$ & $412(33.4)$ & $438(31.6)$ \\
\hline Statutory ACD—care preferencest & $2(10.0)$ & $3(2.2)$ & $92(7.5)$ & $97(7.0)$ \\
\hline Statutory ACD—SDM $†$ & $4(20.0)$ & $19(14.2)$ & $217(17.6)$ & $240(17.3)$ \\
\hline Non-statutory ACD $\dagger$ & $2(10.0)$ & $2(1.5)$ & $164(13.3)$ & $168(12.1)$ \\
\hline ACP documentation completed by healthcare provider or family member only* & $1(5)$ & $8(6)$ & $397(32.2)$ & $406(29.3)$ \\
\hline
\end{tabular}

*A participant with both self-completed documentation and documentation completed by someone else was classified as only having self-completed documentation as self-completed documentation is accorded more weight from a legal perspective.

†A participant could have more than one of these documents.

ACD, advance care directive; ACP, advance care planning; GP, general practice; RACF, residential aged care facility; SDM, substitute decision maker. 


\begin{tabular}{|c|c|c|c|c|}
\hline & Comparison & $\begin{array}{l}\text { Crude OR } \\
(95 \% \mathrm{CI})\end{array}$ & $\begin{array}{l}\text { Adjusted OR } \\
(95 \% \mathrm{Cl})\end{array}$ & $P$ value \\
\hline \multirow[t]{2}{*}{ Gender } & Male & Ref & & 0.094 \\
\hline & Female & $1.41(1.06$ to 1.85$)$ & $1.30(0.95$ to 1.79$)$ & \\
\hline Age (years) & Per year & $1.03(1.02$ to 1.05$)$ & $1.03(1.01$ to 1.05$)$ & 0.009 \\
\hline \multirow[t]{2}{*}{ Multimorbidity } & One & Ref & & 0.897 \\
\hline & Multiple & $1.18(0.61$ to 2.27$)$ & 1.05 (0.48 to 2.27$)$ & \\
\hline \multirow[t]{2}{*}{ Relationship status } & Married/living with partner & Ref & & 0.297 \\
\hline & Other & $0.99(0.75$ to 1.32$)$ & $0.85(0.62$ to 1.16$)$ & \\
\hline \multirow[t]{2}{*}{ Country of birth } & Australia & Ref & & 0.019 \\
\hline & Other & $0.67(0.50$ to 0.90$)$ & $0.68(0.50$ to 0.94$)$ & \\
\hline \multirow[t]{2}{*}{ Setting } & RACF & Ref & & $<0.001$ \\
\hline & Other & $0.12(0.06$ to 0.23$)$ & $0.15(0.06$ to 0.35$)$ & \\
\hline \multirow[t]{4}{*}{ Estimated functional status } & No or some disability & $0.68(0.34$ to 1.39$)$ & $1.14(0.50$ to 2.56$)$ & 0.630 \\
\hline & Moderate disability & $0.77(0.52$ to 1.12$)$ & $0.83(0.55$ to 1.27$)$ & \\
\hline & Severe disability & $1.04(0.76$ to 1.43$)$ & $1.06(0.75$ to 1.49$)$ & \\
\hline & Very severe disability & Ref & & \\
\hline \multirow[t]{2}{*}{ Palliative care } & Yes & Ref & & 0.174 \\
\hline & No & $0.66(0.39$ to 1.10$)$ & $0.68(0.38$ to 1.19$)$ & \\
\hline \multirow[t]{2}{*}{ Jurisdiction } & Common law state for ACD preferences & Ref & & 0.203 \\
\hline & Legislative state for ACD preferences & $0.57(0.29$ to 1.12$)$ & $0.63(0.31$ to 1.28$)$ & \\
\hline \multirow[t]{2}{*}{ ACP programme } & Yes & Ref & & 0.177 \\
\hline & No & $0.34(0.15$ to 0.81$)$ & $0.52(0.20$ to 1.35$)$ & \\
\hline \multirow[t]{2}{*}{ ACP training } & Yes & Ref & & 0.655 \\
\hline & No & $1.10(0.53$ to 2.27$)$ & $1.19(0.55$ to 2.56$)$ & \\
\hline \multirow[t]{2}{*}{ Any ACP policy or guideline } & Yes & Ref & & 0.579 \\
\hline & No & $0.94(0.48$ to 1.89$)$ & $1.22(0.61$ to 2.38$)$ & \\
\hline \multirow[t]{2}{*}{ Any funded ACP support } & Yes & Ref & & 0.545 \\
\hline & No & $1.43(0.75$ to 2.70$)$ & $1.25(0.61$ to 2.56$)$ & \\
\hline
\end{tabular}

$A C D$, advance care directive; $A C P$, advance care planning; RACF, residential aged care facility.

Those who were older and in RACF settings were more likely to have some form of ACP documentation. These patterns suggest that an increasing frequency of encounters with (and transitions between) health and aged care settings as dementia progresses might serve to prompt ACP discussions, and provide impetus for documentation. ${ }^{32}$ Higher likelihood of having ACP documentation among those born in Australia compared with those born outside Australia is consistent with previous research among a broader sample from the same project ${ }^{30}$ and a recent international review of ACP uptake among older adults. ${ }^{33}$

While some form of ACP documentation was present for a substantial proportion of people, only half of the cases in which ACP was documented included an ACD completed by the person themselves. The odds of having ACP documents completed by someone else, compared with a person-completed ACD, were significantly greater in the RACF setting. This perhaps reflects difficulties undertaking ACP when a person is more cognitively and functionally impaired, and a pragmatic concern to ensure that some sort of planning is in place. ${ }^{34}$ However, the extent of this ACP documentation by others on the person's behalf is concerning given the lack of legal frameworks supporting such documents. Further, research has shown discordant preferences for end of life care ${ }^{35}$ between family members and people with dementia, indicating the potential difficulties in making decisions for others without clear guidance. Given the lack of information regarding the person's contemporaneous decision-making capacity at the time of ACP documentation, it is not possible to make inferences about the appropriateness of ACP documentation being made on their behalf. While some, for example, some culturally and linguistically diverse groups,${ }^{30}$ may prefer to defer decision-making to others, the almost $70 \%$ of participants with dementia who had not completed an ACD themselves suggest missed opportunities for promoting ACP discussion earlier in the course of the illness.

ACP programme factors were not predictive of the presence of any form of ACP documentation in the initial logistic regression. However, in the multinomial logistic regression model that considered different types of ACP documentation (person-completed ACD vs ACP documentation by someone else), sites that self-reported having ACP training for staff showed a higher likelihood of the person having no advance 
Table 5 ORs ( $95 \%$ Cls) from multinomial multivariable logistic regression comparing those with self-completed ACD (reference) to those with no ACD or advance care plan, and those who only had ACP completed by someone else

\begin{tabular}{|c|c|c|c|c|c|c|c|}
\hline & & \multicolumn{2}{|c|}{ No ACD or advance care plan } & \multicolumn{2}{|c|}{ ACP completed by someone else } & \multicolumn{2}{|l|}{$P$ value } \\
\hline & & $\begin{array}{l}\text { Crude OR } \\
(95 \% \mathrm{Cl})\end{array}$ & $\begin{array}{l}\text { Adjusted OR } \\
(95 \% \mathrm{Cl})\end{array}$ & $\begin{array}{l}\text { Crude OR } \\
(95 \% \mathrm{CI})\end{array}$ & $\begin{array}{l}\text { Adjusted OR } \\
(95 \% \mathrm{CI})\end{array}$ & Crude & Adjusted \\
\hline \multirow[t]{2}{*}{ Gender } & Male & Ref & & Ref & & 0.061 & 0.237 \\
\hline & Female & $0.71(0.52$ to 0.96$)$ & $0.78(0.55$ to 1.11$)$ & 0.96 (0.68 to 1.37$)$ & 1.05 (0.7 to 1.57$)$ & & \\
\hline Age (years) & Per year & 0.96 (0.95 to 0.98$)$ & 0.97 (0.95 to 0.99) & $1.00(0.97$ to 1.02$)$ & 0.99 (0.97 to 1.02$)$ & 0.001 & 0.030 \\
\hline \multirow[t]{2}{*}{ Multimorbidity } & One & Ref & & Ref & & 0.054 & 0.157 \\
\hline & Multiple & $0.45(0.18$ to 1.09$)$ & $0.52(0.18$ to 1.48$)$ & $0.32(0.12$ to 0.81$)$ & $0.34(0.12$ to 1.02$)$ & & \\
\hline \multirow[t]{2}{*}{$\begin{array}{l}\text { Relationship } \\
\text { status }\end{array}$} & $\begin{array}{l}\text { Married/living with } \\
\text { partner }\end{array}$ & Ref & & Ref & & 0.221 & 0.250 \\
\hline & Other & $0.90(0.65$ to 1.23$)$ & 1.08 (0.75 to 1.55$)$ & $0.72(0.50$ to 1.04$)$ & $0.78(0.52$ to 1.17$)$ & & \\
\hline \multirow[t]{2}{*}{ Country of birth } & Australia & Ref & & Ref & & 0.014 & 0.033 \\
\hline & Other & $1.63(1.17$ to 2.28$)$ & 1.59 (1.11 to 2.26$)$ & $1.19(0.81$ to 1.76$)$ & 1.15 (0.76 to 1.74$)$ & & \\
\hline \multirow[t]{2}{*}{ Setting } & RACF & Ref & & Ref & & $<0.001$ & $<0.001$ \\
\hline & Other & $5.06(2.55$ to 10.0$)$ & $3.17(1.34$ to 7.52$)$ & 0.33 (0.11 to 0.97) & $0.20(0.06$ to 0.66$)$ & & \\
\hline \multirow{4}{*}{$\begin{array}{l}\text { Estimated } \\
\text { functional status }\end{array}$} & No or some disability & $1.13(0.50$ to 2.58$)$ & $0.71(0.28$ to 1.81$)$ & $0.63(0.26$ to 1.53$)$ & 0.65 (0.24 to 1.74$)$ & 0.018 & 0.059 \\
\hline & Moderate disability & 0.91 (0.58 to 1.41$)$ & 0.79 (0.49 to 1.29$)$ & 0.45 (0.27 to 0.74$)$ & $0.43(0.25$ to 0.73$)$ & & \\
\hline & Severe disability & $0.74(0.51$ to 1.07$)$ & 0.72 (0.48 to 1.07$)$ & $0.60(0.41$ to 0.90$)$ & 0.59 (0.38 to 0.90$)$ & & \\
\hline & Very severe disability & Ref & & Ref & & & \\
\hline \multirow[t]{2}{*}{ Palliative care } & Yes & Ref & & Ref & & 0.159 & 0.298 \\
\hline & No & 1.34 (0.76 to 2.39$)$ & 1.62 (0.85 to 3.07$)$ & $0.72(0.38$ to 1.37$)$ & 1.09 (0.55 to 2.15$)$ & & \\
\hline \multirow[t]{2}{*}{ Jurisdiction } & $\begin{array}{l}\text { Common law state } \\
\text { for ACD preferences }\end{array}$ & Ref & & Ref & & 0.148 & 0.379 \\
\hline & $\begin{array}{l}\text { Legislative state for } \\
\text { ACD preferences }\end{array}$ & 1.37 (0.70 to 2.70$)$ & 1.64 (0.81 to 3.35$)$ & 0.53 (0.24 to 1.16$)$ & 0.98 (0.44 to 2.19$)$ & & \\
\hline \multirow[t]{2}{*}{ ACP programme } & Yes & Ref & & Ref & & 0.095 & 0.206 \\
\hline & No & $2.44(1.02$ to 5.82$)$ & $2.25(0.85$ to 5.95$)$ & 0.79 (0.26 to 2.42$)$ & 1.82 (0.57 to 5.80$)$ & & \\
\hline \multirow[t]{2}{*}{ ACP training } & Yes & Ref & & Ref & & $<0.001$ & $<0.001$ \\
\hline & No & $0.47(0.24$ to 0.93$)$ & $0.37(0.17$ to 0.79$)$ & $0.12(0.05$ to 0.29$)$ & 0.09 (0.03 to 0.22$)$ & & \\
\hline \multirow{2}{*}{$\begin{array}{l}\text { Any ACP policy } \\
\text { or guideline }\end{array}$} & Yes & Ref & & Ref & & 0.573 & 0.019 \\
\hline & No & 1.30 (0.66 to 2.57) & 1.39 (0.69 to 2.78$)$ & 1.42 (0.63 to 3.18$)$ & 3.05 (1.39 to 6.69$)$ & & \\
\hline \multirow{2}{*}{$\begin{array}{l}\text { Any funded ACP } \\
\text { support }\end{array}$} & Yes & Ref & & Ref & & 0.434 & 0.526 \\
\hline & No & $0.66(0.35$ to 1.24$)$ & $0.69(0.34$ to 1.39$)$ & $0.89(0.42$ to 1.92$)$ & $0.77(0.34$ to 1.77$)$ & & \\
\hline
\end{tabular}

$A C D$, advance care directive; $A C P$, advance care planning; $R A C F$, residential aged care facility.

care plan, or an ACP document completed by someone else, compared with a person-completed ACD. On the other hand, sites with an ACP policy or guideline in place had relatively higher rates of person-completed ACDs than the no advance care plan or ACP documentation completed by someone else outcomes. These findings may reflect that having a clear policy or guideline in relations to ACP assists health professionals and those accessing the service to engage in ACP through an understood process that applies across the organisation. ${ }^{36}$ ACP training for staff was not shown to influence the likelihood of participants having a self-completed advance care plan. This may reflect difficulties related to adequate training due to high staff turnover, or only limited numbers of staff participating in training. The unexpected negative effect of ACP training on ACD completion may reflect the implementation of a training programme as a first step in responding to an identified deficit in practice.
Alternatively, ACP training developed for the aged care setting might place greater emphasis on consulting with family members in cases where a person is in the advanced stages of dementia, rather than proactive communication with the person themselves in the early stages after diagnosis. ${ }^{34}$ The lack of information regarding the nature of ACP training provided and the extent of implementation across the organisation makes it difficult to draw firm conclusions about this site-level effect, however this is an important area for future research.

\section{Strengths and limitations}

The strengths of this study include extraction of ACD and ACP documentation outcomes directly from health records, and multivariate analysis of personal and ACP programme factors associated with completion of ACDs and ACP documentation. This study also has limitations which should be considered when 
interpreting the results. While sites were recruited from all eight jurisdictions, the distribution of participating sites was not representative across jurisdictions. There were only a small number of people with dementia from the GP setting, with the majority of the sample resided in RACFs. Our findings therefore have particular relevance in the RACF setting. This study also did not consider the contents of identified ACP documents or their clinical usefulness; this is an important consideration for future work. Those who had both self-completed ACDs and ACP documentation completed by someone else were classified as having 'person-completed ACD', thus potentially underestimating the frequency of ACP documentation by others on their behalf.

\section{Implications for practice}

The current study provides insight into current rates of ACD and ACP documentation by persons with dementia in Australia, and may serve as a baseline against which future audits may be compared. Our findings suggest there is a significant population of people with dementia who have no ACP documentation in place, and another group with ACP documentation that has been completed for them by someone else. In the case of a person who never wished to document their own preferences and who has since lost decision-making capacity, this may reflect an appropriate outcome consistent with the individual's values. However, such cases can also be seen as a missed opportunity for promoting ACP earlier in the course of illness to provide people with the choice to plan for their future care needs. This is of particular importance given evidence that there are discrepancies in values and preferences between caregivers of people with dementia, and people with dementia themselves. ${ }^{37} 38$ Further Australian research regarding congruence in care decisions between caregivers of people with dementia and people with dementia themselves is required. Recent studies trialling tailored dementia-specific approaches to ACP that address known barriers to discussion have shown promising early results. ${ }^{39}$ The implementation of clear ACP policies and guidelines at an organisational level is consistent with existing quality standards in Australia, ${ }^{41}$ and can provide a foundation for further initiatives to promote ACP across health and aged care organisations.

\section{CONCLUSIONS}

For people with dementia who have no ACP documentation, or whose ACP documentation is completed by someone else, these findings suggest that more needs to be done to support proactive ACP discussion and create opportunities to document preferences prior to decline in decision-making capacity. However, this should recognise that engaging in ACP is a voluntary process, and that some will prefer to defer such decision-making to others. It is likely that both ACDs completed by the person themselves, and ACP documentation completed by others on a person's behalf, will have relevant roles in promoting optimal care for people with dementia when they are unable to make decisions for themselves. Future research should further investigate the nature of these ACP practices, with the aim of identifying opportunities for supporting people with dementia to express and document their own preferences for future healthcare.

\section{Author affiliations}

${ }^{1}$ Health Behaviour Research Collaborative, School of Medicine and Public Health, Faculty of Health and Medicine, The University of Newcastle, Callaghan, New South Wales, Australia

${ }^{2}$ Priority Research Centre for Health Behaviour, University of Newcastle, Callaghan, New South Wales, Australia

${ }^{3}$ Hunter Medical Research Institute, New Lambton Heights, NSW, Australia

${ }^{4}$ Advance Care Planning Australia, Austin Health, Heidelberg, Victoria, Australia

${ }^{5}$ Australian Centre for Health Law Research, Faculty of Law, Queensland

University of Technology, Brisbane, Queensland, Australia

${ }^{6}$ School of Psychology, University of New South Wales, Sydney, New South Wales, Australia

${ }^{7}$ Australian Research Council Centre of Excellence in Population Ageing Research, University of New South Wales, Sydney, New South Wales, Australia ${ }^{8}$ Neuroscience Research Australia (NeuRA), Sydney, New South Wales, Australia ${ }^{9}$ Faculty of Medicine, Dentistry and Health Sciences, University of Melbourne, Parkville, Victoria, Australia

Acknowledgements We wish to acknowledge the contribution of the National Prevalence Study Advisory Group, and the Study Coordinators and data collectors at each participating site. We also wish to acknowledge Dr Sandy Clarke-Errey of the Statistical Consulting Centre, University of Melbourne, for providing statistical expertise.

Contributors JB was involved in development of the data analysis plan, interpretation of data and drafting the manuscript. MS was involved in data analysis, data interpretation and drafting the manuscript. CS was involved in design, data interpretation and drafting the manuscript. $\mathrm{KD}$ was involved in conception, design, data acquisition, data interpretation and critically revising the manuscript. $\mathrm{KB}$ was involved in the design, data acquisition and critically revising the manuscript. AW was involved in development of the data analysis plan, interpretation of data and drafting the manuscript. BW was involved in design, data interpretation and critically revising the manuscript. LN was involved in conception, design, data acquisition and interpretation and critically revising the manuscript. All authors have read and approved the final manuscript.

Funding This research was funded by the Australian Government Department of Health. JB is supported by a NHMRC-ARC Dementia Research Development Fellowship.

Competing interests None declared.

Patient consent for publication Not required.

Ethics approval Ethics approval was obtained from the Austin Health Human Research Ethics Committee (reference HREC/18/Austin/109) and by sites as required.

Provenance and peer review Not commissioned; externally peer reviewed.

Data availability statement The datasets used and/or analysed for this study are available from the corresponding author upon reasonable request.

Open access This is an open access article distributed in accordance with the Creative Commons Attribution Non Commercial (CC BY-NC 4.0) license, which permits others to distribute, remix, adapt, build upon this work noncommercially, and license their derivative works on different 
terms, provided the original work is properly cited, appropriate credit is given, any changes made indicated, and the use is noncommercial. See: http://creativecommons.org/licenses/by-nc/4. $0 /$.

\section{ORCID iDs}

Jamie Bryant http://orcid.org/0000-0001-9378-5852

Marcus Sellars http://orcid.org/0000-0002-8299-0313

Ben White http://orcid.org/0000-0003-3365-939X

\section{REFERENCES}

1 Chertkow H, Feldman HH, Jacova C. Definitions of dementia and predementia states in Alzheimer's disease and vascular cognitive impairment: consensus from the Canadian conference on diagnosis of dementia. Alzheimers Res Ther 2013;5(Suppl 1):S2.

2 Livingston G, Sommerlad A, Orgeta V, et al. Dementia prevention, intervention, and care. Lancet 2017;390:2673-734.

3 Sampson EL, Candy B, Davis S, et al. Living and dying with advanced dementia: a prospective cohort study of symptoms, service use and care at the end of life. Palliat Med 2018;32:668-81.

4 Mitchell SL, Teno JM, Kiely DK, et al. The clinical course of advanced dementia. N Engl J Med 2009;361:1529-38.

5 Sampson EL, Gould V, Lee D, et al. Differences in care received by patients with and without dementia who died during acute hospital admission: a retrospective case note study. Age Ageing 2006;35:187-9.

6 Sellars M, Chung O, Nolte L, et al. Perspectives of people with dementia and carers on advance care planning and end-of-life care: a systematic review and thematic synthesis of qualitative studies. Palliat Med 2019;33:274-90.

7 Australian Government Department of Health. National framework for action on dementia 2015-2019, 2015.

8 World Health Organisation. Global action plan on the public health response to dementia 2017-2025, 2017.

9 Sudore RL, Lum HD, You JJ, et al. Defining advance care planning for adults: a consensus definition from a multidisciplinary Delphi panel. J Pain Symptom Manage 2017;53:821-32.

10 Piers R, Albers G, Gilissen J, et al. Advance care planning in dementia: recommendations for healthcare professionals. BMC Palliat Care 2018;17:88.

11 Harrison Dening K, Sampson EL, De Vries K. Advance care planning in dementia: recommendations for healthcare professionals. Palliat Care 2019;12:117822421982657.

12 Wendrich-van Dael A, Bunn F, Lynch J, et al. Advance care planning for people living with dementia: an umbrella review of effectiveness and experiences. Int J Nurs Stud 2020;107:103576.

13 Robinson L, Dickinson C, Rousseau N, et al. A systematic review of the effectiveness of advance care planning interventions for people with cognitive impairment and dementia. Age Ageing 2012;41:263-9.

14 Detering KM, Hancock AD, Reade MC, et al. The impact of advance care planning on end of life care in elderly patients: randomised controlled trial. BMJ 2010;340:c1345.

15 Carter RZ, Detering KM, Silvester W, et al. Advance care planning in Australia: what does the law say? Aust Health Rev 2016;40:405-14.

16 Australian Health Minister's Advisory Council. A national framework for advance care directives. Adelaide, 2011.

17 Garand L, Dew MA, Lingler JH, et al. Incidence and predictors of advance care planning among persons with cognitive impairment. Am J Geriatr Psychiatry 2011;19:712-20.

18 Mitchell SL, Kiely DK, Hamel MB. Dying with advanced dementia in the nursing home. Arch Intern Med 2004;164:321-6.
19 White BP, Willmott L, Tilse C, et al. Prevalence of advance care directives in the community: a telephone survey of three Australian states. Intern Med J 2019;49:1261-7.

20 Tay SY, Davison J, Jin NC, et al. Education and executive function mediate engagement in advance care planning in early cognitive impairment. J Am Med Dir Assoc 2015;16:957-62.

21 Dickinson C, Bamford C, Exley C, et al. Planning for tomorrow whilst living for today: the views of people with dementia and their families on advance care planning. Int Psychogeriatr 2013;25:2011-21.

22 Hellström I, Torres S. The "not yet" horizon: Understandings of the future amongst couples living with dementia. Dementia 2016;15:1562-85.

23 Batchelor F, Hwang K, Haralambous B, et al. Facilitators and barriers to advance care planning implementation in Australian aged care settings: a systematic review and thematic analysis. Australas J Ageing 2019;38:173-81.

24 Risk J, Mohammadi L, Rhee J, et al. Barriers, enablers and initiatives for uptake of advance care planning in general practice: a systematic review and critical interpretive synthesis. BMJ Open 2019;9:e030275.

25 Hopkins SA, Bentley A, Phillips V, et al. Advance care plans and hospitalized frail older adults: a systematic review. BMJ Support Palliat Care 2020;10:164-74.

26 Detering KM, Buck K, Ruseckaite R, et al. Prevalence and correlates of advance care directives among older Australians accessing health and residential aged care services: multicentre audit study. BMJ Open 2019;9:e025255.

27 Ruseckaite R, Detering KM, Evans SM, et al. Protocol for a national prevalence study of advance care planning documentation and self-reported uptake in Australia. BMJ Open 2017;7:e018024.

28 Detering KM, Buck K, Sellars M, et al. Prospective multicentre cross-sectional audit among older Australians accessing health and residential aged care services: protocol for a national advance care Directive prevalence study. BMJ Open 2019;9:e031691.

29 Buccheri G, Ferrigno D, Tamburini M. Karnofsky and ECoG performance status scoring in lung cancer: a prospective, longitudinal study of 536 patients from a single institution. Eur J Cancer 1996;32A:1135-41.

30 Sinclair C, Sellars M, Buck K, et al. Association between region of birth and advance care planning documentation among older Australian migrant communities: a multi-center audit study. J Gerontol B Psychol Sci Soc Sci 2020:gbaa127.

31 Jeznach A, Tuokko HA, Garcia-Barrera MA, et al. Findings on advance care plans among cognitively impaired older adults. Can J Aging 2015;34:165-75.

32 Koss C. Encounters with health-care providers and advance Directive completion by older adults. J Palliat Care 2018;33:178-81.

33 de Vries K, Banister E, Dening KH, et al. Advance care planning for older people: the influence of ethnicity, religiosity, spirituality and health literacy. Nurs Ethics 2019;26:1946-54.

34 Phillips JL, West PA, Davidson PM, et al. Does case conferencing for people with advanced dementia living in nursing homes improve care outcomes: evidence from an integrative review? Int J Nurs Stud 2013;50:1122-35.

35 Dening KH, Jones L, Sampson EL. Preferences for end-of-life care: a nominal group study of people with dementia and their family carers. Palliat Med 2013;27:409-17.

36 Sinclair C, Field S, Blake M, et al. An examination of organisational policies for healthcare and lifestyle decisionmaking among Australian aged care providers. Australas J Ageing 2019;38(Suppl 2):90-7.

37 Reamy AM, Kim K, Zarit SH, et al. Understanding discrepancy in perceptions of values: individuals with mild to moderate dementia and their family caregivers. Gerontologist 2011;51:473-83. 
38 Reamy AM, Kim K, Zarit SH, et al. Values and preferences of individuals with dementia: perceptions of family caregivers over time. Gerontologist 2013;53:293-302.

39 Song M-K, Ward SE, Hepburn K, et al. Can persons with dementia Meaningfully participate in advance care planning discussions? A mixed-methods study of spirit. J Palliat Med 2019;22:1410-6.
40 Aged Care Quality and Safety Commission. Standard 2. Ongoing assessment and planning with consumers. Sydney, 2019.

41 Australian Commission on Safety and Quality in Health Care. National consensus statement: essential elements for safe and high-quality end-of-life care in acute hospitals. Sydney, 2014. 